\title{
Alteration of Th17 and Treg cells in patients with unexplained recurrent spontaneous abortion before and after lymphocyte immunization therapy
}

\author{
$\mathrm{Li} \mathrm{Wu}^{*+}$, Li-Hua Luo ${ }^{\dagger}$, Ying-Xin Zhang, Qing Li, Bo Xu, Gui-Xiang Zhou, Hong-Bing Luan and Yu-Sheng Liu*
}

\begin{abstract}
Background: Several types of T cells have been associated with the pathogenesis of unexplained recurrent spontaneous abortion (URSA), including Th1/Th2/Th17/Tregs cell. It has been appreciated that immunotherapy with paternal or third party lymphocytes is an effective method of treatment for URSA patients. The balance of Th1/Th2 cells could be maintained and an increase of Treg cells would be beneficial after immunotherapy; however, the mechanism by which the Th17/Treg balance affects URSA has not yet been fully elucidated.

Methods: Here, we used flow cytometry, liquid chip technology and quantitative real-time PCR (qPCR) methods to characterize Th17/Treg cell populations after immunotherapy. We found that after immunotherapy in URSA patients, the percentage of Th17 cells decreased and the percentage of Treg cells in peripheral blood mononuclear cells (PBMC) increased, as detected by flow cytometry.

Results: Immunotherapy may induce a decrease in the Th17/Treg ratio and the Treg bias, which may be beneficial for the maintenance of pregnancy. The expression level of ROR gamma t, a transcription factor found in Th17 cells, decreased and the expression of the Treg-specific transcription factor Foxp3 increased in peripheral blood as detected by qPCR. Immunotherapy may induce a decrease in the ratio of ROR gamma t to Foxp3 and a Treg cell bias, which would be beneficial for pregnancy maintenance. The secretion of the Treg-associated cytokine TGF-beta, as well as Th2 cytokines, was increased in serum, while the secretion of Th17-associated cytokine IL-17A and Th1 cytokine production was decreased. The Th1/Th2 cytokine ratio significantly decreased. Similarly, the Th17/Treg ratio significantly decreased in the total patient after immunotherapy.

Conclusions: These results indicate that in patients with URSA, immunotherapy with mononuclear cells derived from the baby's father could affect both Th1/Th2 and Th17/Treg balance, and we found that the Th2 and Treg bias would be beneficial for pregnancy, which may lead to a balancing of the Th17/Treg ratio in URSA patients after immunotherapy.
\end{abstract}

Keywords: Th17 cells, Treg cells, Unexplained recurrent spontaneous abortion, Lymphocyte immunization therapy

\footnotetext{
*Correspondence: wuli.0722@163.com; shengzhizhongxin@126.com

†Equal contributors

Center for Reproductive Medicine, Department of Obstetrics and

Gynecology, Anhui Provincial Hospital Affiliated to Anhui Medical University,

Hefei, Anhui, China
}

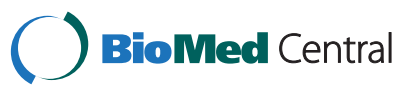

(c) 2014 Wu et al.; licensee BioMed Central Ltd. This is an Open Access article distributed under the terms of the Creative Commons Attribution License (http://creativecommons.org/licenses/by/4.0), which permits unrestricted use, distribution, and reproduction in any medium, provided the original work is properly credited. The Creative Commons Public Domain Dedication waiver (http://creativecommons.org/publicdomain/zero/1.0/) applies to the data made available in this article, unless otherwise stated. 


\section{Background}

An estimated 1-3\% of women have experienced three or more consecutive miscarriages prior to 20 weeks gestation, and this is defined as recurrent spontaneous abortion (RSA) [1]. Unexplained recurrent spontaneous abortion (URSA) affects approximately $50 \%$ of RSA patients, and it is largely associated with the failure of fetomaternal immunologic tolerance. The embryo expresses paternal antigens that are foreign to the mother and therefore may be viewed as an allograft; in normal pregnancy, the embryo is not rejected by the mother's immune system [2]. Literature indicates that altered immunity in URSA is dominated by what is known as the Th1/Th2 hypothesis [3]. The emerging concept of the Th17/Treg balance has challenged the conventional paradigm of Th1/Th2 hypothesis [4,5]. Th17 and Treg T cells have been described as two subsets that are distinct from Th1 and Th2 cells with opposite effects on autoimmunity and transplantation tolerance [6,7]. Lee SK et al. [8] reported that the imbalance between Th17 and Treg cells was correlated with the pathogenesis of URSA. Several reports have suggested that the normal human pregnancy is associated with an elevation of the immunosuppressive Treg subset, and Tregs were recognized to play a crucial role in the maintenance of normal immune tolerance [9-11]. Wang et al. [12] and our previous findings [13] demonstrated that the percentage of Th17 cells were higher in the peripheral blood of patients with URSA, suggesting a potentially negative role of Th17 cells in the maintenance of pregnancy.

Since the 1980s, immunotherapy with paternal or third-party lymphocytes has been an effective treatment for URSA, and it effectively allows for the suppression of the maternal immune responses to the allogeneic fetus in vivo during pregnancy [14-18]. The mechanisms by which immunotherapy works have not yet been fully elucidated, but it may skew the balance of Th1/Th2 cells in patients with URSA who undergo immunotherapy [19-21]. Several studies have indicated that lymphocyte immunotherapy significantly increased the proportion of CD4+/CD25+ Treg cells in peripheral blood mononuclear cells (PBMCs) in women with URSA, and it ultimately improved pregnancy outcome [22]. Several reports found that Th17 cells may play a vital role in rejecting conceptus antigens and therefore may be detrimental for the maintenance of pregnancy. An abnormal balance of Th17/Treg cells may exist in URSA $[8,12,13]$. However, the association between immunotherapy and Th17 cells and the Th17/Treg balance has not yet been fully elucidated.

In this study, we found a decrease in the proportion of Th17 cells in PBMCs and decreases in the expression of Th17-related cytokine IL-17A and Th17-related transcription factor ROR $\gamma$ t mRNA [23] in peripheral blood after immunotherapy with paternal or third party lymphocytes. Furthermore, an increased proportion of Tregs in PBMCs as well as elevated expression of Treg-related cytokine TGF- $\beta$ and Treg-associated transcription factor Foxp3 mRNA [24] were also detected in the peripheral blood. We also found that the Th17/Treg cell ratio was decreased and that the Treg bias improves pregnancy outcome following immunotherapy. After analyzing successful pregnancies that had undergone immunotherapy, we found that the Treg cell bias contributed to the improvement of pregnancy outcome. Taken together, these results help clarify the etiology of immunotherapy with paternal or third party lymphocytes and provide a novel target for the prevention or intervention of spontaneous abortion via regulation of the Th17/Treg balance.

\section{Methods}

\section{Patients}

The study was conducted in compliance with the Declaration of Helsinki and Ethics Committees on Human Research of Anhui Provincial Hospital, an affiliation of the Anhui Medical University. This study had the approval of the Ethics Committee of Anhui Province Hospital; informed consent was obtained before samples were collected (2010 Ethics 5th). All the subjects were patients of the outpatient department of gynecology at Anhui Province Hospital (Hefei, China) between May 2010 and May 2011. Through communication with all couples, they agreed to participate in the study and signed an informed consent form prior to enrollment. This is a prospective study. Twenty patients who had experienced at least three confirmed successive spontaneous early abortions (7-12 weeks of gestation) of unexplained etiology with one partner were recruited to participate in the study. The mean \pm SE deviation age was $28.6 \pm 0.15$ (ranging from 25-37) years, and the median number of miscarriages was 4 (range, 3-7, and all the women had natural conception). None of the participants had a genetic impairment, Mullerian anomaly, hormonal deficiency, metabolic disorder, infectious disease, or autoimmune abnormalities, such as positive antiphospholipid antibodies or lupus anticoagulant, in our systemic workup. In addition, tests for thrombophilic status, such as protein $\mathrm{C}$ activity, protein $\mathrm{S}$ activity, and thrombin anti-thrombin III complex were routinely performed for all patients (Details were showed in Additional file 1: Table S1).

All patients were healthy except for their history of recurrent abortions and were negative for blocking antibodies, which were identified by a one-way mixed lymphocyte culture reaction (responder: patient, stimulator: husband), according to previously reports. Berifly, Lymphocytes were collected from heparinized blood via Ficoll-Hypaque gradient centrifugation. The mitomycin 
C-treated stimulator cells of the husband and responder cells of the patient were mixed and co-cultured in RPMI 1640 containing either pooled human $\mathrm{AB}$ serum or tested serum for 6 days. After a pulse time of 18 hours cultured with $3 \mathrm{H}$-thymidine, the cultured cells were harvested and the DNA synthesis was evaluated by liquid scintillation counting. The blocking effect (BE) was calculated as following $\mathrm{BE}=(1-$ meancpm of culture in tested serum/ mean cpm of culture in $A B$ serum)*100 (\%).

\section{Paternal or third-party lymphocytes immunization}

Donor (husband or third party) lymphocytes were prepared by Ficoll-Paque centrifugation; the cells were washed three times with sterile saline and resuspended in $1 \mathrm{ml}$ at a concentration of $2-3 \times 107 \mathrm{cells} / \mathrm{ml}$. The cells were administered three times intradermally at 3week intervals. We collected the blood after fourth immunization (about 12 weeks after first immunization), and all samples were collected at the same time point. In this study, the lymphocyte immunization therapies were performed every 3 weeks for four times, and then maintaint the lymphocyte immunization therapy every 6 weeks.

\section{Cell preparation}

For Th17 analysis, human PBMCs were suspended at a density of $2 \times 106$ cells $/ \mathrm{mL}$ in complete culture medium (RPMI 1640 supplemented with $100 \mu / \mathrm{ml}$ streptomycin, $100 \mathrm{u} / \mathrm{ml}$ penicillin, $2 \mathrm{~mm}$ glutamine and $10 \%$ heatinactivated fetal calf serum (Gibco, Invitrogen, CA, USA)). The cell suspension was transferred to 24-well plates. Then, cultures were stimulated with phorbol myristate acetate (PMA, $50 \mathrm{ng} / \mathrm{mL}$ ) plus ionomycin $(1 \mu \mathrm{g} / \mathrm{ml})$ for $5-6 \mathrm{hr}$ in the presence of monensin (500 ng/mL; all from Alexis Biochemicals, San Diego, CA, USA). Cells were grown in a $37^{\circ} \mathrm{C}$ incubator at $5 \%$ CO2. After 5-6 hr of culture, the contents of the wells were transferred to $5-\mathrm{mL}$ sterile tubes. The cells were then centrifuged at $350 \mathrm{~g}$ for $5 \mathrm{~min}$. For Treg analysis, PBMCs $(100 \mu \mathrm{L})$ were aliquoted into tubes for further staining.

\section{Surface and intracellular staining}

Cells were aliquoted into tubes and washed once in phosphate buffered saline (PBS). For Th17 analysis, the cells were incubated with fluorescein isothiocyanate (FITC) anti-human CD4 (eBioscience, San Diego, CA, USA) at $4^{\circ} \mathrm{C}$ for $20 \mathrm{~min}$. For Treg analysis, the cells were incubated with PerCP anti-human CD4 (eBioscience, USA) and FITC anti-human CD25 (eBioscience, San Diego, CA, USA) at $4^{\circ} \mathrm{C}$ for $20 \mathrm{~min}$. After the surface staining, the cells were then fixed and permeabilized with Perm/ Fix solution (Beckman Coulter) and were stained with PE anti-human IL-17A (eBioscience) for Th17 detection or PE anti-human Foxp3 (eBioscience, CA, USA) for
Treg detection. All staining was performed according to manufacturer's protocols. Isotype controls were used to enable correct compensation and confirm antibody specificity. Samples were analyzed using a FACS Calibur flow cytometer and Cell Quest Pro software (Beckman Coulter).

\section{Quantitative real-time PCR (qRT-PCR)}

The tissues were collected in RNase-free tubes and total RNA was extracted using Trizol reagent (Invitrogen). RNA samples were quantified with a NanoDrop ${ }^{\text {ma }} 1000$ Spectrophotometer (Thermo scientific) and electrophoresis. Briefly, the peripheral blood cells were homogenized in Trizol reagent, and then chloroform was added to the $1 / 5$ volume of Trizol and mixed thoroughly. The mixture was centrifuged at $12,000 \mathrm{~g}\left(4^{\circ} \mathrm{C}\right)$ for $15 \mathrm{~min}$. The supernatant was collected and mixed with isopropanol at a ratio of $1: 1$ and incubation for $10 \mathrm{~min}$ and was then centrifuged at $14,000 \mathrm{~g}\left(4^{\circ} \mathrm{C}\right)$ for $10 \mathrm{~min}$. The supernatant was removed and $100 \mu \mathrm{l} 75 \%$ ethanol was added to the tubes and mixed thoroughly. After centrifugation at $8,000 \mathrm{~g}\left(4^{\circ} \mathrm{C}\right)$ for $5 \mathrm{~min}$, the supernatant was removed and the tubes were air-dried. cDNA was synthesized using the prime ScriptTM 1st strand cDNA synthesis kit according to the manufacturer's instructions (Fermentas Thermo). Real-time quantification of target mRNA was performed using a SYBR premix Ex TaqTM II kit (Takara) according to the manufacturer's instructions. Briefly, amplification was performed in a total volume of $10 \mu \mathrm{l}$, and each reaction contained $5 \mu \mathrm{l}$ SYBR REmis EX TaqTM, $0.4 \mu \mathrm{l}$ forward and reverse PCR primers, $0.2 \mu \mathrm{l}$ ROX reference Dye II, $1 \mu \mathrm{l}$ cDNA and $3 \mu \mathrm{lddH} 2 \mathrm{O}$. The real time PCR program consisted of an initial step of $10 \mathrm{~s}$ at $95^{\circ} \mathrm{C}$, followed by 40 cycles of denaturing at $95^{\circ} \mathrm{C}$ for $5 \mathrm{~s}$ and extension at $60^{\circ} \mathrm{C}$ for $31 \mathrm{~s}$. All measurements were performed at least three times. GAPDH was used as a housekeeping gene. The following primer sequences were used: RORyt-forward, 5-ACC TCA CCG AGG CCA TTC AG-3 and reverse, 5-TAGG CCC GGC ACA TCC TAA C-3; Foxp3forward, 5-ATC TAC CAC TGG TTC ACA CGC AT-3 and reverse, 5-CTC CAC CCG CAC AAA GCA C-3; GAPDH-forward, 5-GGT GTG AAC CAT GAG AAG TAT GAC A-3 and reverse, 5-GTC CTT CCA CGA TAC CAA AGT TGT-3.

\section{Multiplex fluorochrome assay}

The expression level of cytokines, such as interleukin (IL)-6, IL-10, IL-17A, IL-23, tumor necrosis factor (TNF), TGF- $\beta$ and IFN- $\gamma$, were measured in serum samples, and Bio-Plex Human Cytokine Panel (Bio-Rad Laboratories) was used according to the manufacturer's instructions. The human serum diluent kit (Bio-Rad Laboratories) was employed for purification of the samples. 
Identification and quantification of each specific reaction was performed with a Luminex 100 instrument (Luminex xMAP Technology, Austin). Acquisition conditions were set with a minimum of 100 beads per region. All of the raw data (median fluorescence intensity) from the bead combinations tested were analyzed using StarStation Software 2.3 (Applied Cytometry Systems). A fiveparameter curve fit was used to create each standard curve to obtain the values of sample concentration. The cutoffs for minimum detectable concentration for the cytokines were as follows: $0.5 \mathrm{pg} / \mathrm{mL}$ (IL-6, IL-23), $0.6 \mathrm{pg} / \mathrm{mL}$ (IL-10, IFN- $\gamma$ ), $0.7 \mathrm{pg} / \mathrm{mL}$ (IL-17A) and $1.3 \mathrm{pg} / \mathrm{mL}$ (TNF). The specific antigen- and mitogeninduced cytokine secretions were calculated by subtracting the spontaneous background secretion.

\section{Statistical analysis}

Statistical analysis was conducted with Student's $t$ test. All data analyses were performed by SPSS statistical software (version 13). Data are presented as the means \pm SE. A two-tailed p-value of $<0.05$ was considered to be significant.

\section{Results}

Circulating Th17 Cells, Treg Cells, and the ratio of Th17/ Treg cells in patients with URSA after immunotherapy

The percentage of $1 \mathrm{~L}-17^{+} / \mathrm{CD} 4^{+}$in $\mathrm{PBMC}$ in the total patient population with URSA before immunotherapy was $2.73 \pm 0.68 \%$, and the percentage of this subset after immunotherapy was $1.51 \pm 0.29 \%$ ( $\mathrm{P}<0.01$, paired $t$-test, Figure 1). Thus, the percentage of Th17 cells significantly decreased after immunotherapy compared with that before immunotherapy (Figure 2). We quantitated the percentage of Treg cells within the CD2 $5^{\text {bright }}$ cell population because only these cells represent both fide Treg in human [25,26]. As shown in Figure 3, the percentage of Tregs (CD $4^{+} \mathrm{CD} 25^{\text {bright }}$ Foxp $^{3+} \mathrm{T}$ cells) in PBMC was significantly increased in patients with URSA following $(4.94 \pm 1.38 \%)$ as compared with before $(3.03 \pm$ $0.91 \%$ ) immunotherapy ( $<<0.01$, paired $t$-test, Figure 1$)$. Thus, the percentage of Treg significantly increased after immunotherapy (Figure 2). The mean Th17/Treg ratio in all patients with URSA before immunotherapy was 0.98 but dropped to 0.33 after immunotherapy $(\mathrm{P}<0.05$, Figure 1). Therefore, the mean Th17/Treg ratio significantly decreased after immunotherapy compared with the
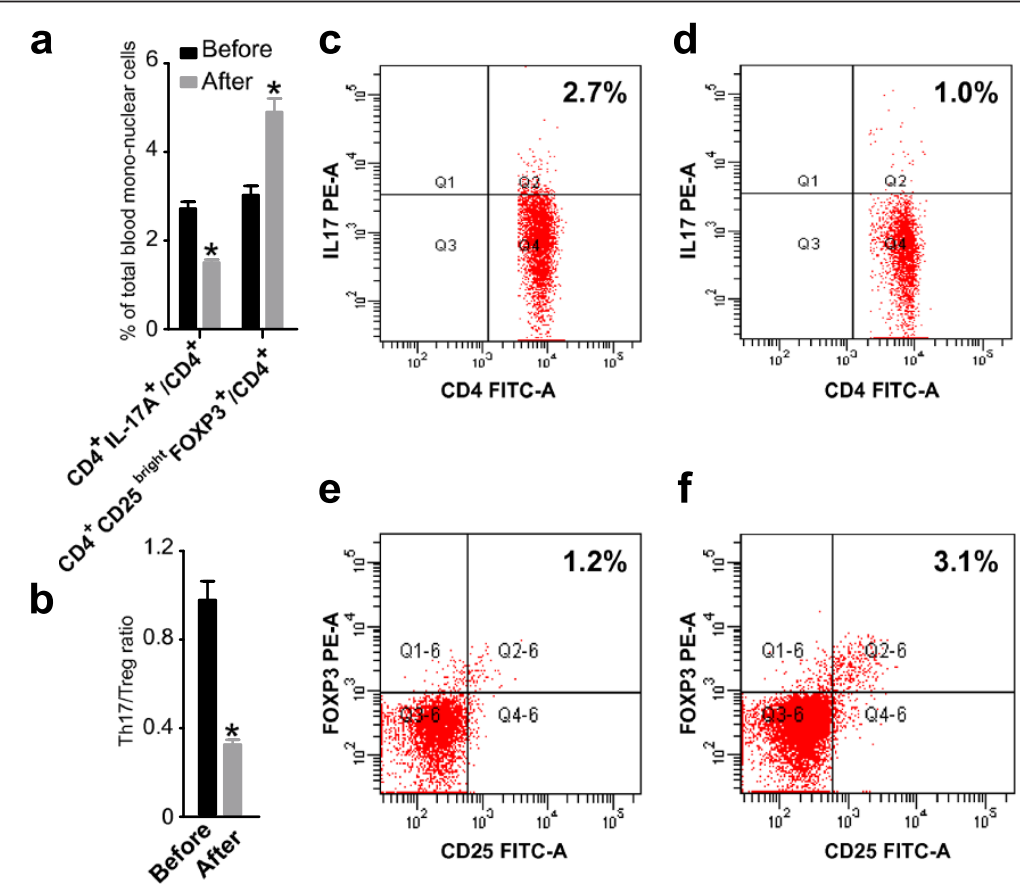

e

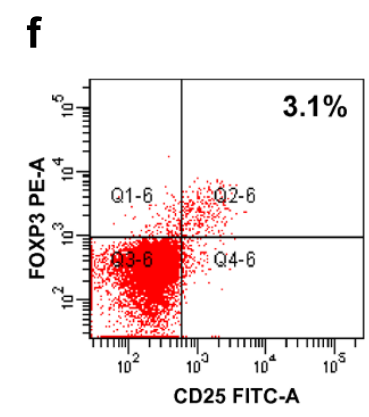

Figure 1 The percentages of Th17 and Treg cells in peripheral blood mononuclear cells and the Th17/Treg ratio varied with immunotherapy. The percentage of Th17 and Treg cells in peripheral blood mononuclear cells were detected by flow cytometry in the total patient population before and after immunotherapy, respectively. (a) The percentage of Th17 cells in peripheral blood mononuclear cells significantly decreased after immunotherapy $\left(P<0.01\right.$, paired $t$-test). Bar represents the CD4 $4^{+} / \mathrm{LL}-17 \mathrm{~A}^{+}$cell frequency and values of the means $\pm S$. E. The percentage of Treg cells in peripheral blood mononuclear cells significantly increased after immunotherapy $(P<0.01$, paired $t$-test). Bar represents the frequency of $\mathrm{CD}^{+} / \mathrm{CD} 25$ bright/Foxp3 ${ }^{+}$cells and the means \pm S.E. are shown. (b) The Th17/Treg ratio in peripheral blood mononuclear cells significantly decreased after immunotherapy ( $P<0.01$, paired $t$-test). Bar represent Th17/Treg ratio in total patients before and after immunotherapy and values of means \pm S.E. Representative CD4+/L-17A + flow cytometry plots in patients are shown before (c) and after (d) immunology. Representative CD4+/CD25bright/Foxp3+ flow cytometry plots in patients are shown before (e) and after (f) immunology. 

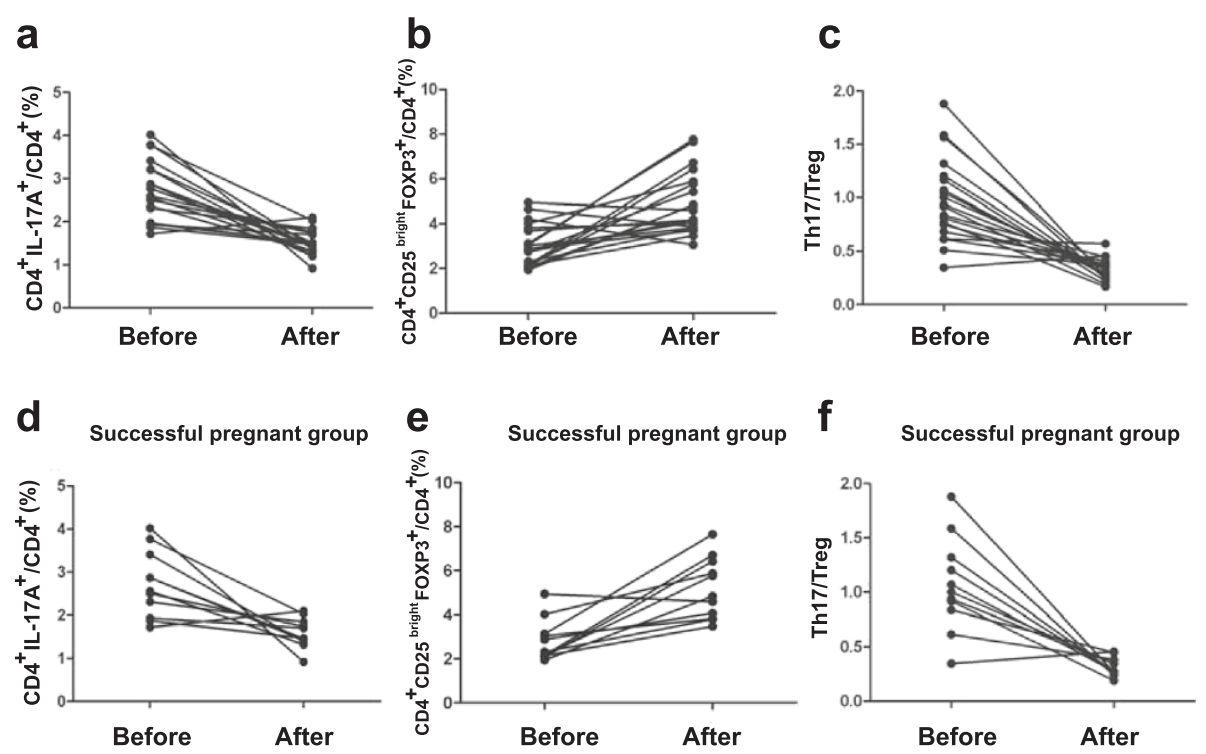

Figure 2 The change of Th17 and Treg cells in peripheral blood mononuclear cells and the Th17/Treg ratio varies in total patients and patients with a successful pregnancy after immunotherapy. The detailed variation of CD4+/lL-17A + (a), CD4+/CD25bright/Foxp3+ (b) and Th17/Treg ratio (c) in each patient before and after immunotherapy is shown in line chart. The detailed variation of CD4+/L-17A + (d), CD4+/CD25bright/Foxp3 + (e) and Th17/Treg ratio (f) in each patient with a successful pregnancy after immunotherapy is shown in the line chart.

ratio before immunotherapy $(\mathrm{P}<0.01$, paired $t$-test), as shown in Figure 3.

\section{Circulating Th17 cells, Treg cells, and the ratio of Th17 and Treg cells in URSA patient with successful pregnancies following immunotherapy}

To date, 13 of the 20 patients had recent pregnancies. Of these 13 patients, the pregnancy continued in 11 patients (successful group) (83.3\%), while the remaining 2 cases underwent repeated abortion (unsuccessful group). Of the 11 patients with successful pregnancies, 8 patients delivered babies and the remaining 3 are still pregnant (their gestational weeks $[\mathrm{Gw}]$ are 20, 28 and 23). The mean percentage of $\mathrm{CD} 4^{+} / \mathrm{IL}-17^{+} \mathrm{T}$ cells of the successful group before immuno- therapy was $2.72 \%$ of total PBMC, and the mean percentage after immunotherapy was $1.58 \%$ (Figure 3). The percentage of Tregs $\left(\mathrm{CD} 4{ }^{+} \mathrm{CD} 25^{\text {bright }} \mathrm{Foxp}^{3+} \mathrm{T}\right.$ cells) was significantly higher in the successful group $(5.19 \pm 1.38 \%)$ after than before $(2.80 \pm 0.95 \%, \mathrm{P}<0.01)$ immunotherapy (Figure 3$)$. The mean of the Th17/Treg ratio in the successful group before immunotherapy was 1.06 , and the mean ratio after immunotherapy was 0.32 (Figure 3).

Thus, in the successful group, the percentage of Th17 cells (Figure 2) was significantly lower and the percentage of Tregs (Figure 2) was significantly higher after immunotherapy. The ratio of Th17/Treg cells (Figure 2) was significantly lower after immunotherapy.

\section{The cytokines measured in serum samples}

The concentrations of Th1-type cytokines IFN- $\gamma$ and TNF- $\alpha$ were significantly decreased in the serum of patients with URSA before immunotherapy $(1.97 \pm 0.69$ and $4.66 \pm 1.32 \mathrm{pg} / \mathrm{ml})$ than after immunotherapy $(1.03 \pm$ 0.37 and $2.28 \pm 0.96 \mathrm{pg} / \mathrm{ml}$ ). The concentration of Th2type cytokine IL-10 before immunotherapy was $6.32 \pm$ 2.46 and after immunotherapy was $10.87 \pm 4.32 \mathrm{pg} / \mathrm{ml}$, which was a significant increase. Th17-type cytokines such as IL-6 and IL-23 were significantly decreased after immunotherapy; before immunotherapy, IL-6 and IL-23 were $1.60 \pm 0.49$ and $17.94 \pm 9.76 \mathrm{pg} / \mathrm{ml}$, respectively, and after immunotherapy were $0.89 \pm 0.34$ and $7.78 \pm 3.43$ $\mathrm{pg} / \mathrm{ml}$. Additionally, the concentration of TGF- $\beta$ was significantly higher after immunotherapy (3909.05 \pm $1248.35 \mathrm{pg} / \mathrm{ml})$ versus before $(2469.83 \pm 1058.71 \mathrm{pg} / \mathrm{ml})$. IL-17A (Fig. 4f) was significantly decreased after immunotherapy $(1.57 \pm 0.78 \mathrm{pg} / \mathrm{ml})$ compared with that before immunotherapy $(4.32 \pm 1.40)(\mathrm{P}<0.01$, paired $t$-test $)$. As shown in Figure 4.

Th1/Th2 balance in patients with URSA who underwent immunotherapy had been reported, and we also found that there may be a unique balance between Th1type cytokines, such as IFN- $\gamma$, and Th2-type cytokines, such as interleukin IL-10, as shown in Figure 5. The concentration of Th17-type cytokine IL-17A was significantly lower and Treg-type cytokine TGF- $\beta$ was significantly higher after immunotherapy compared with concentration before immunotherapy. The ratio of Th17/Treg cytokines 

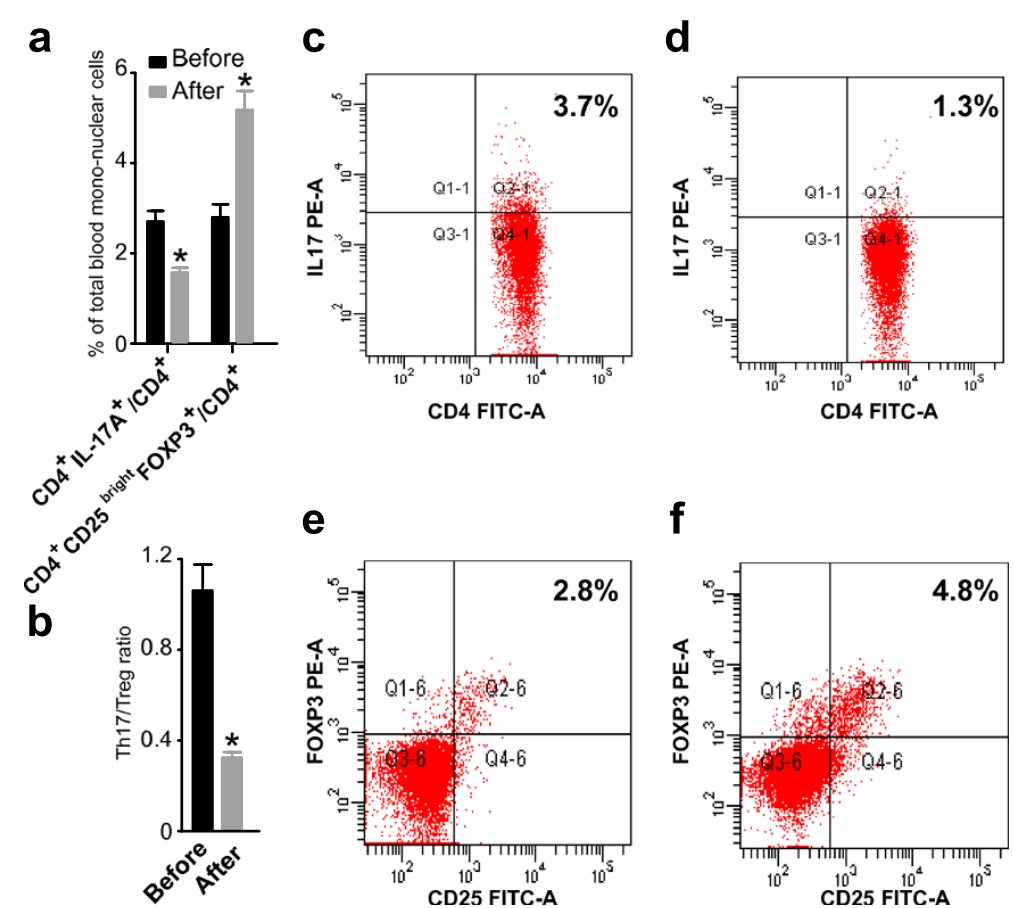

e

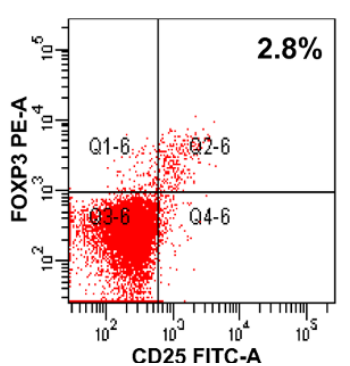

f

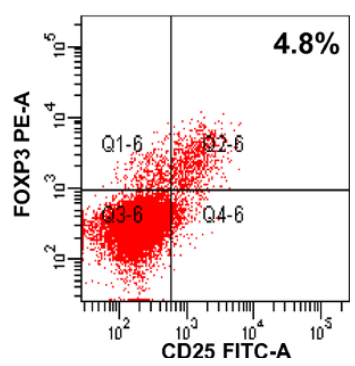

Figure 3 The percentage of Th17 and Treg cells in peripheral blood mononuclear cells and the Th17/Treg ratio varies in patients with a successful pregnancy after immunotherapy. The percentage of Th17 and Treg cells in peripheral blood mononuclear cells were detected by flow cytometry in patients with successful pregnancy after immunotherapy. To date, 13 of the 20 patients have become newly pregnant. Of the 13, the 11 patients did not miscarry (successful group). (a) The percentage of Th17 cells in peripheral blood mononuclear cells significantly decreased after immunotherapy. The percentage of Treg cells in peripheral blood mononuclear cells significantly increased after immunotherapy $(P<0.01$, paired $t$-test). Bar represents the CD4+/L-17A + cell frequency and the means \pm S.E. are indicated (b) The Th17/Treg ratio in peripheral blood mononuclear cells significantly decreased after immunotherapy $(P<0.01$, paired $t$-test). Bar represent the frequency of CD4+/CD25bright/Foxp3+ cells and the means \pm S.E. are indicated. Representative CD4+/IL-17A + flow cytometry plots from patients with successful pregnancies were shown before (c) and after (d) immunotherapy. Representative CD4+/CD25bright Foxp3+ flow cytometry plots from patients with successful pregnancies were shown before (e) and after (f) immunotherapy.
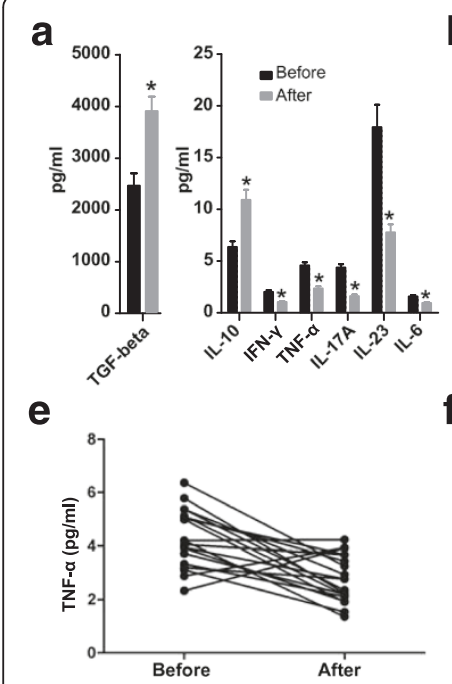

b

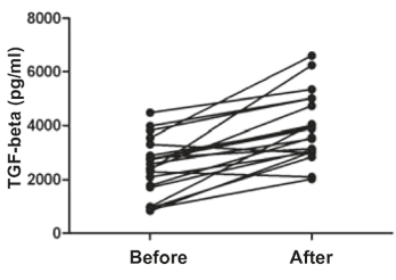

f

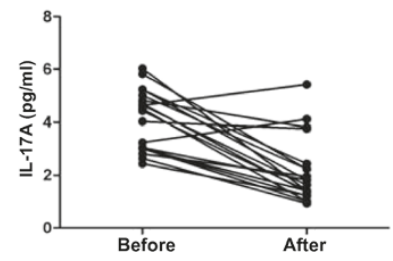

C

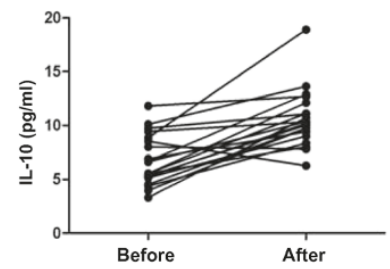

g

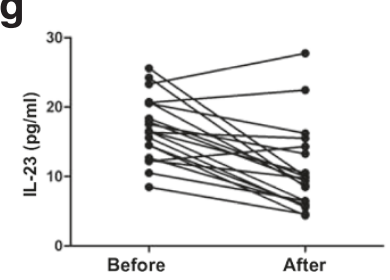

d

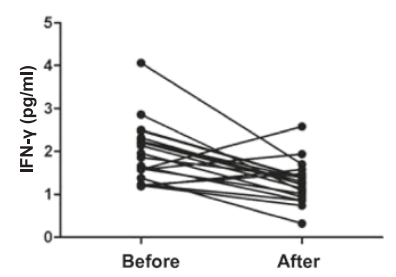

h

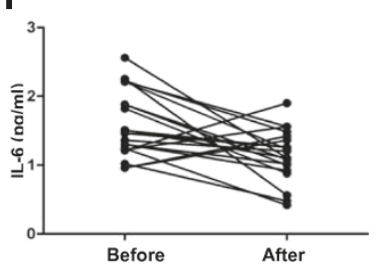

Figure 4 The interleukins/cytokines were detected by multiplex fluorochrome assay in serum samples from the total patients before and after immunotherapy. (a) The content of TGF- $\beta$, IL-10, IFN- $\gamma$, TNF- $\alpha$, IL-17A, IL-23, and IL-6 in serum varied before and after immunotherapy. The detailed variation of TGF- $\beta$ (b), IL-10 (c), IFN-ץ (d), TFN-a (e), IL-17A (f), IL-23 (g), and IL-6 (h) in each patient before and after immunotherapy is shown in the line chart. 
was significantly lower after immunotherapy as compared with before immunotherapy (Figure 5).

\section{The mRNA expression of RORyt and FOXP3}

The most important transcription factor for the differentiation of naïve T cells into Tregs is the forkhead box P3 (Foxp3) [24]. Similarly, retinoic acid-related orphan receptor $t(R O R \gamma t)$ [23] is a crucial transcription factor for the development of Th17 cells. The mRNA expression of Foxp3 was significantly increased after immunotherapy. Meanwhile, the mRNA expression of ROR $\gamma \mathrm{t}$ was significantly decreased after immunotherapy, as shown in Figure 6.

\section{Discussion}

Several studies characterizing immunotherapy in URSA patients reported that the outcome of subsequent pregnancies was apparently improved by injection of paternal or a third party's leukocytes [14-18], although the findings of Ober C et al. [27] suggested this treatment is ineffective. The efficacy of immunotherapy might be related to the immune response by allogeneic lymphocytes and might not be simply a placebo effect. From a worldwide metaanalysis study, it has been indicated that immunization may be highly effective, although only for a small number of patients with URSA [28,29]. In our center, $80-90 \%$ of URSA patients who underwent immunotherapy successfully delivered a baby. Although immunotherapy was considered possibly efficacious, the underlying mechanisms have not yet been fully elucidated.

The Th1/Th2 balance in circulating $\mathrm{T}$ cells has been reported to be shift in favor of Th2 dominance during normal pregnancy, whereas the Th1 dominance has been found to be associated with reproductive failures such as URSA [30,31]. Although Wilczynski JR et al. reported that Th1/Th2 bias was not correlated with subsequent pregnancy success in the patients who accepted paternal lymphocyte immunization (PLI) [32], most related studies suggested that Th1/Th2 imbalance plays an important role in URSA and is a target for treatment of PLI
[19-21]. Tomokazu Yokoo et al. [20] and Qiu L et al. [21] reported that immunotherapy with the husband's mononuclear cells could induce a dominant state of Th2 cells in URSA patients. Th1 type cytokines, such as TNF- $\alpha$ and IFN- $\gamma$, are detrimental to pregnancy at high concentrations [21]. In the present study, we also found that TNF- $\alpha$ and IFN- $\gamma$ were significantly decreased after immunotherapy. Additionally, Th2-type cytokine IL-10 was significantly increased after immunotherapy [21]. The induction of Th2 bias might be correlated with the successful continuation of pregnancy in patients with URSA who undergo immunotherapy with lymphocytes derived from the baby's father.

Several studies support our findings that the proportion of $\mathrm{CD} 4{ }^{+} \mathrm{CD} 25^{+}$Treg cells in peripheral blood lymphocytes was significantly lower in URSA women than in normal (non-pregnant) control subjects, which suggests that $\mathrm{CD} 4^{+} \mathrm{CD} 25^{+}$Treg cells might contribute to the mechanisms mediating maternal immune tolerance of conceptus antigens, and therefore, Treg cells might contribute to the maintenance of pregnancy $[25,26]$. The reciprocal developmental pathway for the generation and the opposing effects of Th17 and Treg cells may affect the balance between these cell subsets in patients with URSA $[4,5,12]$. Investigators suggested a potentially deleterious role for Th17 cells in pregnancy [12,13]. Our previous data [13] also implicated that the imbalance between Th17 and Treg cells may play an important role in the pathogenesis of URSA. Hui Yang et al. [22] demonstrated that lymphocyte immunization significantly increased the percentage of Tregs in peripheral blood in women with URSA, contributing to improved pregnancy outcome. The data suggested that Tregs may be a novel target in URSA therapy.

Progesterone is required for the establishment and maintenance of pregnancy, and the link between progesterone and the immune system is also established. Several reports suggested that the immunological effects of progesterone are mediated by progesterone-induced blocking factor (PIBF). Through the Il-4 receptor, PIBF induces a Th2-

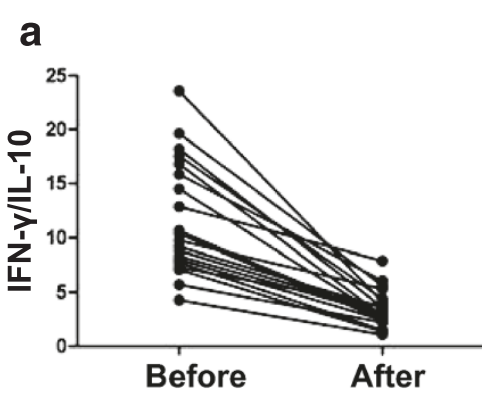

\section{b}

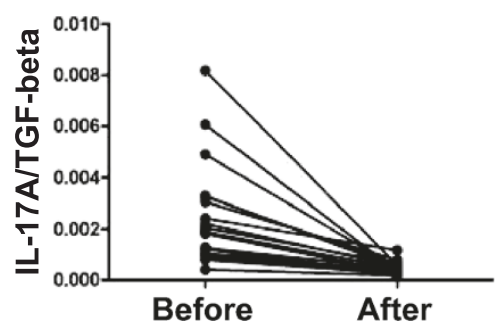

Figure 5 The ratio of IFN- $\gamma /$ IL-10, and IL-17A/TGF- $\beta$ varied in total patients before and after immunotherapy. The detailed variation of the ratio of IFN- $\gamma / \mathrm{IL}-10$ (a), and IL-17A/TGF- $\beta$ (b) in each patient is shown in the line chart. 


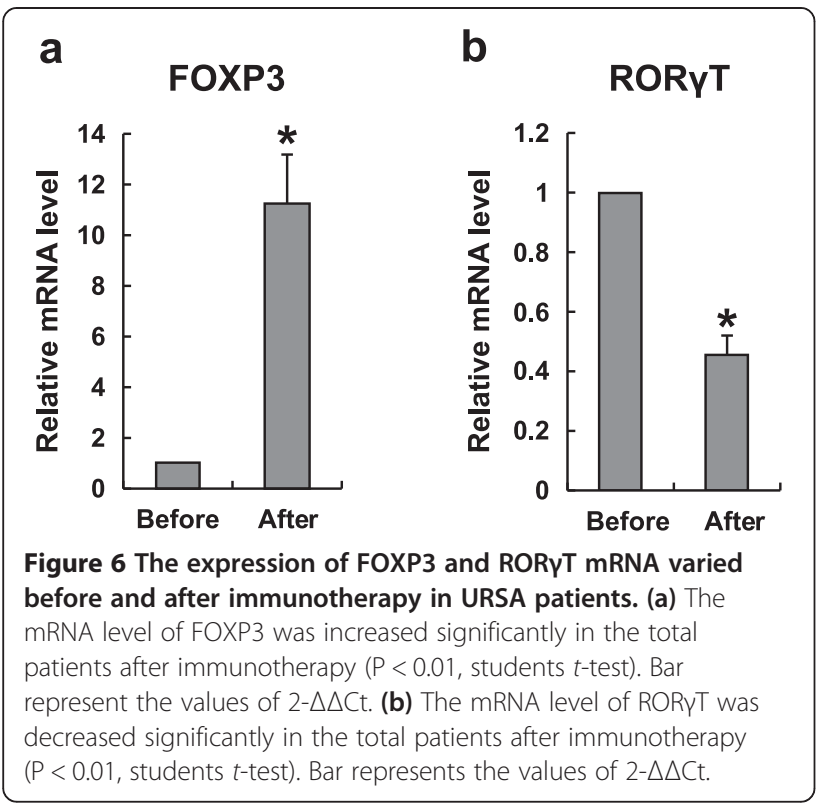

dominant cytokine reponse with increased production of IL-3, IL-4 and IL-10 [33,34]. The treatment of progesterone in Th1-like T cells led to increased expression of IL-4. mRNA and production [35]. These results indicated that PIBF might play a role in regulation of Th1/Th2 balance during lymphocyte immunotherapy of URSA.

In present study, we first analyzed Th17 cells, Treg cells, and the Th17/Treg balance in URSA patients following lymphocyte immunization. Subsequently, we detected a significant decrease in Th17 cells, a significant increase in Treg cells in PBMCs, and a significant decrease in the Th17/Treg ratio in URSA patients after immunotherapy. Furthermore, this phenomenon was reinforced by the demonstration that URSA patients could have a successful subsequent pregnancy after immunization therapy. It has been reported that increased IL-23 or IL-6 production and decreased TGF- $\beta$ production might cause an increase in Th17 cells and a decrease in Treg cells in the uterus $[10,12,36,37]$. We detected the Th17-related soluble cytokines, such as IL-6, IL-17A, and IL-23 in serum, and found that levels of these cytokines were significantly decreased after immunotherapy. Similarly, levels of Tregassociated cytokines IL-10 and TGF- $\beta$ were significantly higher after immunotherapy. Tregs exert their function partly through secretion of the anti-inflammatory cytokines IL-10 and TGF- $\beta$. Additionally, TGF- $\beta$ can promote Foxp3 expression by inducing Treg differentiation from CD4+/CD25 + T cells [38-42]. This is in accordance our data that the expression of Foxp3 mRNA was higher after immunotherapy compared with before immunotherapy. Conversely, the expression of ROR $\gamma \mathrm{t}$ mRNA was lower after immunotherapy.

\section{Conclusions}

In this context, we initially analyzed the Treg cells bias against Th17 cells and whether it may play a role in the maintenance of pregnancy. It is possible that immunotherapy affects the Th17 and Treg cell balance in patients. Therefore, up-regulation of the Treg population and down-regulation of the Th17 population might contribute to the outcome of pregnancy. The data suggest that regulating the balance of Th17/Treg may be a novel target in URSA therapy. The limitation of this study is the number of samples is small, and further study is required.

\section{Additional file}

Additional file 1: Table S1. Clinical characteristics of the patients.

\section{Abbreviations}

FITC: Fluorescein isothiocyanate; Foxp3: Forkhead box p3; Gw: Gestational weeks; IFN-ү: Interferony; IL: Interleukin; PBMC: Peripheral blood mononuclear cells; PBS: Phosphate buffered saline; PMA: Phogrbol12 -myristate13-acetate; q PCR: Quantitative real-time PCR; ROR $y$ t: RETINOID-related orphan receptor gamma; RSA: Recurrent spontaneous abortion; TGF- $\beta$ : Transforming growth factor- $\beta$; Th1: T helper 1 cells; Th2: T helper 2 cells; Th17: T helper 17 cells; TNF-a: Tumor necrosis factor; Treg: Regulatory T cells; URSA: Unexplained recurrent spontaneous abortion.

\section{Competing interests}

The authors declare that they have no competing interests.

\section{Authors' contributions}

LW and LHL conducted the experiment and data collection, participated in the design of the study, and drafted the manuscript. YXZ and QL participated in the processing of the experiment and collection data. BX performed the statistical analysis and the diagramming. GXZ and HBL conducted the interpretation of the data and there vision for important intellectual content and grammar. YSL conceived of the study, participated in its design and coordination, and helped to draft the manuscript. All the authors read and approved the final manuscript.

\section{Acknowledgements}

The authors would like to thank a professional service used for language corrections.

This research was supported by grants from the Anhui provincial health office (09C211), Anhui provincial Education Department (KJ201Z172) and AnHui Medical University (011xkj073). The funders had no role in study design, data collection and analysis, decision to publish, or preparation of the manuscript.

Received: 7 April 2014 Accepted: 23 July 2014

Published: 3 August 2014

\section{References}

1. Sierra S, Stephenson M: Genetics of recurrent pregnancy loss. Semin Reprod Med 2006, 24:17-24.

2. Erlebacher A: Why isn't the fetus rejected? Curr Opin Immunol 2001, 3:590-593.

3. Raghupathy R, Makhseed M, Azizieh F, Hassan N, Al-Azemi M, Al-Shamali E: Maternal Th1 and Th2 type reactivity to placental antigens in normal human pregnancy and unexplained recurrent spontaneous abortions. Cell Immunol 1999, 196:122-130.

4. Bettelli E, Carrier Y, Gao W, Korn T, Strom TB, Oukka M, Weiner HL, Kuchroo VK: Reciprocal developmental pathways for the generation of pathogenic effector or TH17 and regulatory T cells. Nature 2006, 441:235-238.

5. Mucida D, Park Y, Kim G, Turovskaya O, Scott I, Kronenberg M, Cheroutre H: Reciprocal Th17 and regulatory $T$ cell differentiation mediated by retinoic acid. Science 2007, 317:256-260. 
6. Afzali B, Lombardi G, Lechler RI, Lord GM: The role of T helper 17 (Th17) and regulatory $T$ cells (Treg) in human organ transplantation and autoimmune disease. Clin Exp Immunol 2007, 1481:32-46.

7. Jin D, Zhang L, Zheng J, Zhao Y: The inflammatory Th17 subset in immunity against self and non-self antigens. Autoimmunity 2008, 41:154-162.

8. Lee SK, Kim JY, Hur SE, Kim CJ, Na BJ, Lee M, Gilman-Sachs A, Kwak-Kim J: An imbalance in interleukin-17-producing $T$ and Foxp3+ regulatory $T$ cells in women with idiopathic recurrent pregnancy loss. Hum Reprod 2011, 11:2964-2971.

9. Somerset DA, Zheng Y, Kilby MD, Sansom DM, Drayson MT: Normal human pregnancy is associated with an elevation in the immune suppressive CD25 + CD4 + regulatory T-cell subset. Immunology 2004, 112:38-43.

10. Sasaki Y, Sakai M, Miyazaki S, Higuma S, Shiozaki A, Saito S: Decidual and peripheral blood CD4 + CD25+ regulatory $T$ cells in early pregnancy subjects and spontaneous abortion cases. Mol Hum Reprod 2004, 10:347-353.

11. Aluvihare VR, Kallikourdis M, Betz AG: Regulatory T cells mediate maternal tolerance to the fetus. Nat Immunol 2004, 5:266-271.

12. Wang WJ, Hao CF, Yi-Lin, Yin GJ, Bao SH, Qiu LH, Lin QD: Increased prevalence of T helper 17 (Th17) cells in peripheral blood and decidua in unexplained recurrent spontaneous abortion patients. J Reprod Immunol 2010, 84:164-170.

13. Liu YS, Wu L, Tong XH, Wu LM, He GP, Zhou GX, Luo LH, Luan HB: Study on the relationship between Th17 cells and unexplained recurrent spontaneous abortion. Am J Reprod Immunol 2011, 65:503-511.

14. Mowbray JF, Gibbings C, Liddell H, Reginald PW, Underwood JL, Beard RW: Controlled trial of treatment of recurrent spontaneous abortion by immunization with paternal cells. Lancet 1985, 8435:941-943.

15. Unander AM, Lindholm A: Transfusion of leucocyte-rich erythrocyte concentrates: a successful treatment in selected cases of habitual abortion. Am J Obstet Gynecol 1986, 154:516-520.

16. Gatenby PA, Cameron K, Simes RJ, Adelstein S, Bennett MJ, Jansen RP, Shearman RP, Stewart GJ, Whittle M, Doran TJ: Treatment of recurrent spontaneous abortion by immunization with paternal lymphocytes: results of a controlled trial. Am J Reprod Immunol 1993, 29:88-94.

17. Lin Q, Zhao A, Zhou H: Immunotherapy of primary habitual abortion. Zhonghua Fu Chan Ke Za Zhi 1996, 31:351-352.

18. Jin LP, Li DJ, Zhang JP, Wang MY, Zhu XY, Zhu Y, Meng Y, Yuan MM: Adoptive transfer of the paternal antigen-hyporesponsive $T$ cells induces maternal tolerance to the allogeneic fetus in abortion prone matings. $\mathrm{J}$ Immunol 2004, 173:3612-3619.

19. Szpakowski A, Malinowski A, Głowacka E, Wilczyński JR, Kolasa D, Dyński M, Tchórzewski H, Zeman K, Szpakowski M: The influence of paternal lymphocyte immunization on the balance of Th1/Th2 type reactivity in women with unexplained recurrent spontaneous abortion. Ginekol Po 2000, 71:586-592.

20. Yokoo T, Takakuwa K, Ooki I, Kikuchi A, Tamura M, Tanaka K: Alteration of $\mathrm{TH} 1$ and $\mathrm{TH} 2$ cells by intracellular cytokine detection in patients with unexplained recurrent abortion before and after immunotherapy with the husband's mononuclear cells. Fertil Steril 2006, 85:1452-1458.

21. Qiu L: Study on changes of serumT helper cell type 1 and type 2 cytokines after active immunotherapy in women with unexplained habitual abortion. Zhonghua Fu Chan Ke Za Zhi 2001, 36:408-410.

22. Yang H, Qiu L, Di W, Zhao A, Chen G, Hu K, Lin Q: Proportional change of CD4 + CD25+ regulatory T cells after lymphocyte therapy in unexplained recurrent spontaneous abortion patients. Fertil Steril 2009, 92:301-305.

23. Ivanov II, McKenzie BS, Zhou L, Tadokoro CE, Lepelley A, Lafaille JJ, Cua DJ, Littman DR: The orphan nuclear receptor ROR-gammat directs the differentiation program of pro-inflammatory IL-17+ T helper cells. Cell 2006, 126:1121-1133.

24. Kim JM, Rudensky A: The role of the transcription factor Foxp3 protein in the development of regulatory T cells. Microbes Infect 2004, 6:745-751.

25. Seol HJ, Oh MJ, Lim JE, Jung NH, Yoon SY, Kim HJ: The role of CD4 + CD25bright regulatory $T$ cells in the maintenance of pregnancy, premature rupture of membranes, and labor. Yonsei Med J 2008, 3:366-371.

26. Tilburgs T, Roelen DL, van der Mast BJ, de Groot-Swings GM, Kleijburg C, Scherjon SA, Claas FH: Evidence for a selective migration of fetus specific $\mathrm{CD} 4^{+} \mathrm{CD} 25^{\text {bright }}$ regulatory $\mathrm{T}$ cells from the peripheral blood to the decidua in human pregnancy. J Immunol 2008, 8:5737-5745.

27. Ober C, Karrison T, Odem RR, Barnes RB, Branch DW, Stephenson MD, Baron B, Walker MA, Scott JR, Schreiber JR: Mononuclear-cell immunization in prevention of recurrent miscarriages: A randomised trial. Lancet 1999, 354:365-369.

28. Pandey MK, Agrawal S: Induction of MLR-Bf and protection of fetal loss: a current double blind randomized trial of paternal lymphocyte immunization for women with recurrent spontaneous abortion. Int Immunopharmacol 2004, 4:289-298.

29. Worldwide collaborative observational study and meta-analysis on allogeneic leucocyte immunotherapy for recurrent spontaneous abortions. Recurrent Miscarriage Immunotherapy Trialists Group. Am J Reprod Immunol 1994, 32:55-72.

30. Makhseed M, Raghupathy R, Azizieh F, Omu A, Al-Shamali E, Ashkanani L: Th1 and Th2 cytokine profiles in recurrent aborters with successful pregnancy and with subsequent abortions. Hum Reprod 2001, 10:2219-2226.

31. Makhseed M, Raghupathy R, Azizieh F, Al-Azemi MM, Hassan NA, Bandar A: Mitogen-induced cytokine responses of maternal peripheral blood lymphocytes indicate a differential Th-type bias in normal pregnancy and pregnancy failure. Am J Reprod Immunol 1999, 5:273-281.

32. Wilczyński JR, Radwan P, Tchórzewski H, Banasik M: Immunotherapy of patients with recurrent spontaneous miscarriage and idiopathic infertility: does the immunization-dependent Th2 cytokine overbalance really matter? Arch Immunol Ther Exp (Warsz) 2012, 60:151-160.

33. Kozma N, Halasz M, Polgar B, Poehlmann TG, Markert UR, Palkovics T, Keszei M, Par G, Kiss K, Szeberenyi J, Grama L, Szekeres-Bartho J: Progesterone-induced blocking factor activates STAT6 via binding to a novel IL-4 receptor. J Immunol 2006, 176:819-826.

34. Szekeres-Bartho J, Wegmann TG: A progesterone-dependent immunomodulatory protein alters the Th1/Th2 balance. J Reprod Immunol 1996, 31:81-95.

35. Piccinni MP, Giudizi MG, Biagiotti R, Beloni L, Giannarini L, Sampognaro S, Parronchi P, Manetti R, Annunziato F, Livi C: Progesterone favors the development of human $T$ helper cells producing Th2-type cytokines and promotes both IL-4 production and membrane CD30 expression in established Th1 cell clones. J Immunol 1995, 155:128-133.

36. Nakashima A, Ito M, Shima T, Bac ND, Hidaka T, Saito S: Accumulation of IL-17-positive cells in decidua of inevitable abortion cases. Am J Reprod Immunol 2010, 64:4-11.

37. Arruvito L, Billordo A, Capucchio M, Prada ME, Fainboim L: IL-6 trans-signaling and the frequency of CD4 + FOXP3+ cells in women with reproductive failure. J Reprod Immunol 2009, 82:158-165.

38. Chen W, Jin W, Hardegen N, Lei KJ, Li L, Marinos N, McGrady G, Wahl SM: Conversion of peripheral CD4 + CD25 naive T cells to CD4 + CD25+ regulatory $T$ cells by TGF-betainduction of transcription factor Foxp3. J Exp Med 2003, 198:1875-1886.

39. Zheng SG, Wang J, Horwitz DA, Cutting edge: Foxp3 + CD4 + CD25+ regulatory $\mathrm{T}$ cells induced by $\mathrm{LL}-2$ and TGF-beta are resistant to Th17 conversion by IL-6. J Immunol 2008, 180:7112-7116.

40. Xu L, Kitani A, Fuss I, Strober W, Cutting edge: Regulatory T cells induce CD4 + CD25-Foxp3- T cells or are self-induced to become Th17 cells in the absence of exogenous TGF-beta. J Immunol 2007, 178:6725-6729.

41. Zheng SG, Gray JD, Ohtsuka K, Yamagiwa S, Horwitz DA: Generation ex vivo of TGF-beta-producing regulatory T cells from CD4 + CD25precursors. J Immunol 2002, 169:4183-4189.

42. Zheng SG, Wang JH, Gray JD, Soucier $H$, Horwitz DA: Natural and induced CD4 + CD25+ cells educate CD4 + CD25- cells to develop suppressive activity: the role of IL-2, TGF-beta, and IL-10. J Immuno/ 2004, 172:5213-5221.

doi:10.1186/1477-7827-12-74

Cite this article as: Wu et al:: Alteration of Th17 and Treg cells in patients with unexplained recurrent spontaneous abortion before and after lymphocyte immunization therapy. Reproductive Biology and Endocrinology 2014 12:74. 